\title{
Building Disaster Resilience: Steps Toward Sustainability
}

\author{
Susan L. Cutter
}

Hazards and Vulnerability Research Institute, Department of Geography, University of South Carolina, Columbia, SC 29208, USA; E-Mail: scutter@sc.edu; Tel.: +1 8037771590; Fax: +1 8037774972

Submitted: 2 September 2013| In revised form: 5 December 2013| Accepted: 18 December 2013 | Published: 29 January 2014

\begin{abstract}
Disaster losses continue to escalate globally and in many regions human losses (death, injury, permanent displacement) often exceed the economic toll. Current disaster policies are reactive with a short-term focus-respond and rebuild as quickly as possible and in the same way after the event. Such policies ignore the longer-term approach of building disaster-resilient communities, in which investments made now show financial and social returns later by reducing the impact of disasters. This article provides a vision for resilient nations in 2030 based on three recent policy reports. It highlights the necessary steps towards achieving sustainability using the lens of disaster resilience as the pathway towards strengthening communities' ability to prepare and plan for, absorb, respond to, and recover from present and future disasters.
\end{abstract}

Keywords: disaster resilience; Hyogo Framework for Action; risk management; sustainable development

\section{Introduction}

Some hazards, such as hurricanes, tornados, wildfires, and avalanches occur during specific time periods of the year, while others, like earthquakes do not. Some hazards are place-specific-the tectonically active Pacific Rim, coastal environments-while others, especially severe storms, are ubiquitous and found almost everywhere. Human-made hazards can occur anywhere, as can health-related hazards such as pandemics. The result: no single person or place is totally immune from hazards or their adverse impacts. As more and more people move to hazardous environments such as coasts and floodplains, the potential for increasing disaster risk intensifies as more people and infrastructure are placed in harm's way. In the United States, migration to the coasts, along with an increasing and aging population and public infrastructure that is equally old and beyond its design limit, set the stage for greater impacts from hazards. This scene is replicated in many other places such as Japan, and EU countries. In other world regions rapid urbanization and growth of mega-cities where more than half of the world's population now lives and where local wealth is most concentrated are amplifying disaster risk as well.

We need not look further back than the last couple of years to see the escalating losses associated with disasters. The year 2012 is considered a moderate year for losses, with global economic losses totaling US $\$ 170$ 
billion, slightly above the ten-year average, although fatalities were lower than normal [1]. Globally, there is a worrisome trend in increasing weather-related losses, a trend that is clear even when the raw data are normalized by inflation and GDP [2]. When using other normalization proxies (such as inflation, GNI per capita, insurance penetration, or building stock development) the increase remains, averaging $\$ 750$ million per year in annual losses [3]. In the U.S., the number of individual events producing economic losses exceeding a billion dollars has increased. In 2010, for example, there were 4 billion dollar events; in 2011 there were 14; and in 2012, there were 11 [4]. Trends in human losses (people killed, injured, displaced, or affected) during the last decade fluctuate and illustrate the effect of a single catastrophic event-2004 Indian Ocean tsunami, 2008's Cyclone Nargis, and the 2010 Haiti earthquake. Without these large events, there is an apparent decreasing trend in disaster fatalities, with 2012 recording one of the lowest numbers of fatalities from disasters in more than a decade [5].

Disaster losses are occurring at a time of slower economic growth (regionally and globally), reductions in coastal and riverine defenses that protect communities from flooding and storm surge, and the increasing impacts of climate change from local to regional to global levels. The impacts of disasters are greatest in already impoverished communities, regions, or countries and such impacts will increase in the future. Communities and the nations that contain them cannot continue to shoulder the financial or social burdens of these losses each year-they are not sustainable in either the short or longer term [6]. Communities and nations face difficult choices (fiscal, social, environmental) about their existing vulnerabilities, present and future security, and quality-of-life.

This paper summarizes the actions needed to enhance disaster resilience based on recent reports by the United Nations [7], the UK Government Office for Science [8], and the U.S. National Research Council [9]. It argues that disaster resilience is the pathway for linking disaster risk management and the longterm sustainability of communities, through a series of action-oriented steps that involve combinations of top-down (internationally and nationally-driven) and bottom-up (community-based) strategies. The idea is certainly not new within the academic literature [10, 11], with some researchers re-conceptualizing resilience as "bouncing forward not bouncing back" to some previous condition [12]. However, within the policy realm linking disaster risk, resilience, and sustainability, this notion is relatively new and represents a shift in thinking regarding disaster risk management.

\section{Linking Disaster Risk Management and Sustainable Communities}

Linking disaster risk management and sustainable development begins with understanding the com- monalities in each construct and their geographic and temporal manifestations. Disaster risk management is the "process that weighs policies, plans, and actions for reducing the impact of disasters on people, property, and the environment" ([9], p. 28). It includes the identification of hazards and exposures, assessments of the risk in terms of potential losses, the development of capacities and implementation of strategies to prevent, reduce, mitigate, recover, or prepare for disasters, and evaluation of the effectiveness of these policies and programs.

Sustainability is the potential to maintain the long term well-being of communities based on social, economic, and environmental requirements of present and future generations. It stresses the interdependencies of environmental protection, human needs, and societal well-being [13,14], acknowledging the primary goal of improving the human condition without harming the environment. In the context of hazards and disasters, "sustainability means that a locality can tolerate-and overcome-damage, diminished productivity, and reduced quality of life from an extreme event without significant outside assistance" ([15], p. 4). How and where development should proceed in communities if they are to become sustainable begins with a set of principles that foster sustainable mitigation. These principles maintain and enhance environmental quality and quality of life, foster local resilience, recognize that vibrant communities are essential, ensure intra- and intergenerational equity, and adopt local consensus building.

Fundamentally, resilience is a capacity measure that can be viewed as sector-focused, systems-based, or, applied more broadly to a community, defined as systems of systems where the various componentsenvironment, infrastructure, social, economic, institutional and so forth-are integrated and mutually supportive. There is rich and growing body of literature on resilience, ranging from definitional clarifications to conceptual frameworks to applications of the resilience concept in specific environments such as cities or to topical areas such as climate change or sustainability [16-23]. Despite such robust research there is no universal agreement on the specific definition of disaster resilience, yet there is some consensus on its broad parameters, specifically the capacity to recover from or improve functions after a hazard event. For example, an US NRC report defined resilience as "the ability to prepare and plan for, absorb, recover from, or more successfully adapt to actual or potential adverse eve-nts" ([9], p. 1). This is similar to the UK Foresight report that defines resilience as "the ability of a system and its component parts to anticipate, absorb, accommodate, or recover from the effects of a hazardous event in a timely and efficient manner, including through ensuring the preservation, restoration, or improvement of its essential basic structures and functions" ([8], p. 17).

What links disaster risk management to sustainability 
is resilience (Figure 1). The present focus on the disaster cycle especially response and recovery must be targeted more broadly on strategies to manage disaster risk in both the long and short terms $[24,25]$. There are many different paths for achieving longterm viability and self-sufficiency of communities from a hazards and disaster perspective. Such pathways are designed to enhance resilience by instituting a culture of resilience through managing residual disaster risk, reducing vulnerability, having strong leadership from government and civil society, implementing institutional reform of policies and practices at all levels, building local capacity including peer-to-peer learning, developing and deploying tools and metrics for monitoring progress, and reducing gaps in our scientific information, data, and observation systems. Disasters retard development gains through the destruction of livelihoods and community assets, increase poverty, and stimulate repopulation in high-risk (and largely unsustainable) damaged areas. Disasters, therefore, become perverse incentives for communities and nations to divert from normal development processes in order to facilitate response and recovery. From a policy perspective then, thinking about and planning for resilience as part of disaster risk management and sustainable development strategies and programs becomes an important element in the process of achieving sustainable and thus disaster resilient communities.

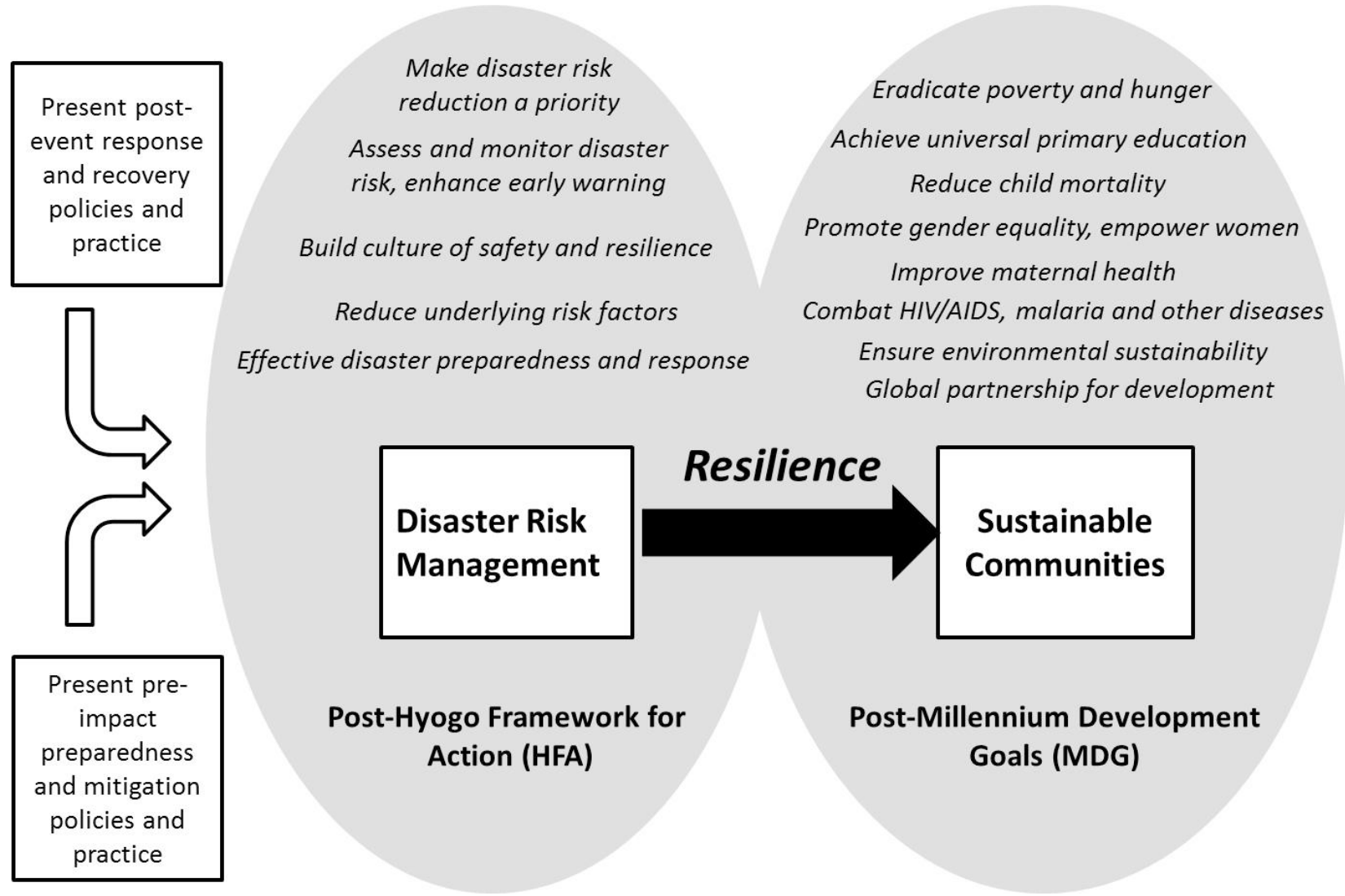

Figure 1. The path to a disaster resilient future.

\section{Why is Resilience so Important Now?}

Extreme natural events (either unprecedented magnitudes or intensities of natural hazards, or the unprecedented consequences of more routine hazards), may become increasingly normal or routine under changing climatic conditions or changes in economic circumstances and social conditions [26]. Coupled with the increasing interdependence and interconnectedness of society, hazards, while local in origin, can cascade into global events with national and international policy implications $[27,28]$.

Low probability, high consequence events including highly improbable ones take on more policy interest as these events become more probable [29-31]. From a policy perspective, such events pose significant management challenges. The complexity, interconnectedness, uncertainty, and unforeseen consequences associated with these types of events make them difficult to solve. Incomplete or contradictory information, changing conditions and requirements that are not easily recognized by decision makers, and the complex interdependencies of the individual facets of the problem themselves raise a set of questions as to how one can encourage investments in risk reducing measures prior to these unthinkable or unpredictable events $[32,33]$. These so-called wicked problems are so interconnected that in solving one aspect of the issue, another problem one might ensue. For example, in partial response to the Fukushima Dai'ichi 
nuclear meltdown, Germany announced the closure of all of its nuclear facilities by 2020 . The closure of nuclear power plants producing electricity raises a wicked problem for nations who are struggling to provide safe energy and reduce greenhouse gas emissions that contribute to climate change [34-36]. What is the alternative? What risks are involved in that choice? Will the nation be better or worse off? Disaster risk cannot be completely eliminated as there will always be some residual risk that requires management. This premise underscores that a proactive approach to risk management and improving disaster resilience is the only policy and the pragmatic option if we are to reduce the impacts of disaster losses in the long run.

Globalization and environmental change are normally studied independently, but it is the interaction of these processes that creates double exposures which in turn explain the uneven outcomes of disaster impacts [37]. These impacts are scaledependent, ranging from the local community to the global, necessitating different governance structures and management regimes at all geographic scaleslocal, regional, national, international-and units of analysis ranging from the individual to the state [38]. For example, the widening gap in income equality between and within nations reduces local and national capacities to prepare for and respond to disasters by lowering social protection options. The eradication of poverty is perhaps the key to achieving resilience and more sustainable development along with socially inclusive productive and effective governance [39]. Urbanization is escalating worldwide, leading to decreasing resilience in world cities. In $2010,52 \%$ of the world's 6.9 billion inhabitants lived in urban areas, mostly in the less developed world. By 2030, more than $60 \%$ of the world's population (projected to be 8.3 billion) will live in urban areas, primarily in Asia [8]. Many of the major cities are located along the coasts, on inland waterways, or in active seismic regions-areas susceptible to cyclones, flooding, and earthquakes. With the increasing exposure and likely impacts associated with climate change, globally more people are in harm's way than ever before. Unless cities and nations become more resilient, the disaster toll in terms of human lives and economic losses will escalate, potentially reversing the downward trend in fatalities over the last decade.

Finally, the Hyogo Framework for Action (HFA) is nearing the end of its 10-year plan. Global consultations (termed HFA2) are already underway to develop a post-2015 disaster risk framework that includes not only disaster risk reduction, but disaster resilience as well. These efforts will be presented at the World Conference for Disaster Risk Reduction in Japan in early 2015. Simultaneously, the Millennium Development Goals will also be completed at the end of 2015 and consultations on a post-2015 Development Agenda also are underway. One of the universal goals, ending poverty, has a specific disaster risk reduction target: building resilience and reducing deaths from natural disasters [7]. How the HFA2 goals for risk reduction and resilience are reflected in the post-2015 Sustainable Development Goals is uncertain. The incorporation of resilience into the preparatory meetings on the Post-Hyogo Framework for Action (HFA2) and the Sustainable Development Goals illustrates how important the concept of resilience is to both disaster risk management and sustainable development. This linkage enables movement from short-term thinking and strategies to longer-term, more sustainable practices that not only empower communities, but enable them to improve the human condition and reduce disaster risk.

\section{Building Resilience}

In reviewing the key findings of the three reports [7-9] a general scientific consensus emerges on the need for disaster risk management and improving resilience at all levels of governance. The main findings are summarized in Table 1 and briefly described below. First, reducing risk requires a process of risk identification, development of a strategy to deal with risk, and keeping the strategy flexible and current $[9,40]$. Risk management also necessitates multiple collaborators and stakeholders and a mix of structural or construction-related (e.g. levees, retrofitting buildings) and non-structural (land use, insurance) tools to ensure resilient infrastructure.

Second, there is a need to demonstrate that investments in resilience will yield measureable short/longterm benefits, but existing disaster loss and damage data need improvements in order to do so. For example, there is no consistent standard for measuring losses or which losses should be counted (e.g. deaths, property, decline in nature's services, or cultural assets in the community) [41-43].

Third, resilience has many different facets (economic, infrastructure, environmental, social, institutional, organizational, psychosocial) and objects of study (individuals, buildings, sectors, systems, communities, cities) [44]. While some national and international efforts are underway to measure community resilience [45-47], at present these efforts are not consistent with one another and often do not agree on what needs to be measured. Some important elements include critical infrastructure performance after disasters, social factors that influence the capacity to recover, the ability of structures to withstand the impact from disasters as related directly to building codes and their enforcement, the ability of businesses and markets to recover, and caring for special needs populations in times of crises.

Fourth, communities vary in their size, composition, and the range of hazards they are exposed to. A onesize-fits-all strategy for enhancing resilience does not consider the uniqueness and complexities of com- 
munities' physical and social structures. Instead, efforts should be directed towards building strong local capacity so that community members are engaged in disaster policy and practice, help communicate risk, adopt risk reduction measures, and plan for the worst, but strive for the best when a disaster hits their community [48]. Finally, many communities and nations do not have an overall vision or coordinating strategy for disaster resilience. A need exists for strong and complementary governance from local, state, and federal policies so they don't work at crosspurposes [49]. Policies at all levels also need to take longer-term views rather than address short-term political expediencies [50].

There are a number of enabling conditions that can help foster disaster resilience at local to national levels. First and foremost, there must be leadership and the political will to embark on a different path for managing disaster risk. Without such leadership, resilience actions will be short-lived and will not achieve the longer-term desired benefits. Another enabling condition is governmental engagement in risk reduction, one of the leading pillars of the Hyogo Framework for Action (see Figure 1). Such engagement should occur at all levels (from local to national) so that the combined governmental efforts are complimentary and working toward a common goal, rather than working at cross-purposes. Similarly, risk reduction should entail cross-sector linkages, involving private interests and civil society. Communities must be willing (and able) to engage in peer to peer learning and to take good ideas from one place and adapt them to their own circumstances. Lastly, resilience must be integrated into overall planning efforts that address infrastructure deficits, improve livelihoods and economic opportunities, and reduce social inequalities, ideals embodied in the Millennium Development Goals.

Table 1. Actions to increase disaster resilience.

- Manage risks with flexible strategies and multiple tools

- Integrate disaster risk management and planning into day-to-day activities

- Encourage public-private cooperation in risk management

- Use complimentary approaches and tools (structural, non-structural)

- Develop an essential framework of codes, standards and guidelines that increase resilience of structures

- Implement risk-based pricing of insurance

- Improve the accuracy and consistency of disaster data

- Establish and improve a national/international databases on disaster-related information

- Document disaster deaths, injuries, property loss, impacts on economic activity

- Improve valuation of community assets including ecosystem services

- Estimate future disaster losses for planning

- Improve risk management information and integrated models of exposure and vulnerability metrics

- Measure resilience and chart progress toward achieving it

- Establish a baseline of resilience for nation and communities

- Create metrics for measuring progress and effectiveness of actions

- Ensure robust analyses of the effectiveness of actions and programs to build resilience

- Build strong local capacity

- Foster early engagement stakeholders and residents in the risk management process and collaborative problem solving

- Create and financially support broad-based community resilience coalitions

- Ensure local governments adhere to modern zoning laws, and adopt and enforce building codes

Share experiences, learn from other communities, innovate

- Create an overall vision or coordinating strategy for disaster resilience

- Incorporate resilience as a guiding principle in practice and programs at all government levels

- Review resilience policy and programs and undertake self-assessments to ensure coordination of federal to local efforts

- Develop and share guidance on resilience initiatives from global to local scales;

- Incentivize private sector and non-governmental organizations to engage in resilience activities

Source: [7-9]. 


\section{How Do We Get There?}

Many different avenues are available for achieving the long-term viability and self-sufficiency of communities with respect to hazards and disasters. The pathway for achieving the vision of a resilient nation in 2030 for the United States, for example, begins with the aspiration to establish a culture of resilience through leadership from the federal government with a full and clear commitment to disaster resilience [9]. In order to achieve such a goal a number of steps would be needed; steps that are targeted to national and local governments, stakeholders, and citizens. First, in addition to this recognizable culture across the nation, there would be the knowledge and understanding that communities (and individuals) would be the first line of defense in enhancing resilience by taking responsibility for their actions in managing (or mismanaging) disaster risk. Second, leadership is an important component in fostering resilience, and there would be national leadership in all federal agencies and in Congress as well as local and state advocates championing the values of disaster resilience. Such leadership would insure that infrastructure systems are upgraded and redundant in order to lessen the impacts of disasters. It also would ensure a periodic review of federal, state, and local programs or policies to insure that resilience actions are supported not reduced. Third, community-led resilience efforts would receive federal, state, and regional investments and support. Reliance on underfunded and solely volunteer efforts would become the exception, not the rule. Fourth, to more fully manage risks, local zoning ordinances would be enacted and enforced, as would building codes and retrofit standards. Such enforcement would enhance disaster resilience at the local level as these ordinances and codes are under local jurisdictions, not state or federal control. Fifth, site specific risk information would be readily available at all scales and effectively communicated to relevant stakeholders from local to national levels. And finally, insurance premiums would become risk-based, so that individuals and communities with the highest risk would bear a greater share of the cost of risk premiums. This would enable post-disaster recovery to be funded primarily through private capital and insurance payouts rather than federal resources. More importantly, such actions would provide the financial mechanism to ensure that communities and individuals take responsibility for their risk decision making.

If these proactive steps were taken, we could see a reduction in the per capita federal cost of responding to disasters in the U.S. We would also see a decline in overall disaster losses because of these long-term investments in resilience.

Disaster resilience links disaster risk management and sustainable development, especially in the developing world. Unlike the national example, the global path requires some transformative shifts in the business-asusual model, one that is more planet-sensitive, peoplecentric, and harmonized with local-national approaches such as those outlined above for the U.S. The five pillars of the global transformation include: to leave no one behind; put sustainable development at the core; transform economies for jobs and inclusive growth; build peace and transparent and accountable institutions; and forge new global partnerships [51]. If such a transformative shift takes place, by 2030 the world would see increased resilience and improved quality of life. There would be fewer people in extreme poverty, more children living beyond the age of five, less mortality from childbirth, more sustainable use of natural resources, improvements in education and employment, and more participatory governance and accountability at all levels (local to regional to national). More significantly, such actions would result in 220 million fewer people suffering the crippling effects of disasters ([51], p. 19).

\section{Conclusions}

The present focus on the disaster cycle must be targeted more broadly on strategies to build resilience as the transition to sustainability. The mechanisms involve managing disaster risk, undertaking institutional reform of policies and practices at all governance levels, building local capacity, development and deployment of tools and metrics for monitoring progress, and investment in the reduction of gaps in our scientific information, data, and observation systems. As the World Bank recently stated, "the international community should lead by example by further promoting approaches that progressively link climate and disaster resilience to broader development paths, and funding them appropriately" ([52], p. 9). The most significant challenges to achieving the transformation are institutional, political will, and leadership and these challenges exist at global to local scales.

Enhancing disaster resilience requires the coordinated efforts of individuals, families, communities, the private sector, and government at all levels. The path to disaster resilience requires a blending of top-down (global to local) and bottom-up (local to global) approaches as no single person, agency, or institution has all the responsibility for improving resilience; must be a collective effort with shared responsibilities. Achieving disaster resilience will not be cheap or easy, but it is becoming both an economic necessity and a moral imperative. We must have the political will to move from the present focus on shortterm disaster response to a longer-term vision of a more sustainable future that embodies the basic principles of resilience as outlined here. When we have achieved some success in enhancing our collective resilience to disasters, we will secure the future livelihoods and prosperity for our children's future. 


\section{References and Notes}

1. MunichRe. Topics Geo 2012: Natural Catastrophes 2012 Analyses, Assessments, Positions. Munich, Germany. 2013. Available from: http://www. munichre.com/publications/302-07742_en.pdf (accessed on 15 January 2014).

2. Neumayer E, Barthel F. Normalizing economic loss from natural disasters: A global analysis. Global Environmental Change. 2010;21(1):13-24.

3. Eichner J. Loss trends-How much would past events cost by today's standards? In: Topics Geo: Natural Catastrophes 2012. Munich, Germany. MunichRe; 2013. pp 56-59. Available from: http://www.munichre. com/publications/302-07742_en.pdf (accessed on 15 January 2014).

4. NOAA (National Oceanic and Atmospheric Administration). Billion-Dollar Weather/Climate Disasters. Available from: www.ncdc.noaa.gov/billions/events (accessed on 29 November 2013).

5. International Federation of Red Cross and Red Crescent Societies. World Disasters Report 2013. Geneva, Switzerland: International Federation of Red Cross and Red Crescent Societies; 2013.

6. Gall M, Borden KA, Emrich CT, Cutter SL. The unsustainable trend of natural hazard losses in the United States. Sustainability. 2011;3(11):2157-2181.

7. United Nations Office for Disaster Risk Reduction (UNISDR). Making Cities Resilient Report 2012. Geneva, Switzerland: United Nations Office for Disaster Risk Reduction; 2012.

8. United Kingdom Foresight. Foresight Reducing Risks of Future Disasters: Priorities for Decision Makers, Final Project Report. London, UK: Government Office for Science; 2012.

9. United States National Research Council. Disaster Resilience: A National Imperative. Washington, DC, USA: The National Academies Press; 2012.

10. Coaffee J, Wood DM, Rogers P. The Everyday Resilience of the City: How Cities Respond to Terrorism and Disaster. Hampshire, UK: Palgrave Macmillan (New Security Challenges Series); 2008.

11. O'Brien K, Hayward B, Berkes F. Rethinking social contracts: Building resilience in a changing climate. Ecology and Society. 2009;14(2):12. Available from: www.ecologyandsociety.org/vol14/iss2/art12/ (accessed on 15 January 2014).

12. Manyena SB, O'Brien G, O'Keefe P, Rose J. Disaster resilience: $A$ bounce back or a bounce forward ability. Local Environment. 2011;16(5):417-424.

13. World Commission on Environment and Development. Our Common Future. Oxford, UK: Oxford University Press; 1987.

14. National Research Council. Our Common Journey: A Transition toward Sustainability. Washington, DC, USA: The National Academies Press; 1999.

15. Mileti D. Disasters by Design: A Reassessment of Natural Hazards in the United States. Washington, DC, USA: Joseph Henry Press/National Academies
Press; 1999.

16. Fiksel J. Sustainability and resilience: Toward a systems approach. Sustainability: Science, Practice, Policy. 2006;2(2):14-21.

17. Nelson DR, Adger WN, Brown K. Adaptation to environmental change: Contributions of a resilience framework. Annual Review of Environmental Resources. 2007;32:395-419.

18. Klein RJT, Nicholls RJ, Thomalla F. Resilience to natural hazards: How useful is this concept? Environmental Hazards. 2003;5(1-2):35-45.

19. Vale LJ, Campanella TJ. The Resilient City: How Modern Cities Recover from Disaster. New York, NY, USA: Oxford University Press; 2005.

20. Turner II BL. Vulnerability and resilience: Coalescing or paralleling approaches to sustainability science? Global Environmental Change. 2010;20(4): 570-576.

21. Paton D, Johnston D. Disaster Resilience: An Integrated Approach. Springfield, IL, USA: Charles C. Thomas; 2006.

22. Cutter SL, Barnes L, Berry M, Burton C, Evans E, Tate $\mathrm{E}$, Webb J. A place-based model for understanding community resilience to natural disasters. Global Environmental Change. 2008;18(4):598-606.

23. Leichenko $R$. Climate change and urban resilience: Current Opinion in Environmental Sustainability. 2011;3(3):164-168.

24. Rogers P. Development of resilient Australia: Enhancing the PPRR approach with anticipation, assessment and registration of risks. Australian Journal of Emergency Management. 2011;26(1):54-58.

Note: the disaster cycle represents one perspective on disaster risk management. In the US the cycle includes preparedness, response, recovery, and mitigation. In Australia disaster risk management is focused on prevention, preparedness, response, and recovery.

25. Emergency Planning College. A Guide to GIS Applications in Integrated Emergency Management. London, UK: UK Government; 2005. Available from: https://www.gov.uk/government/uploads/system/up loads/attachment_data/file/61203/gis_guide_acro6.pdf (accessed on 15 January 2014).

Note: in the UK, the integrated emergency management six elements-anticipate, assess, prevent, prepare, respond, and recover.

26. Field CB, Barrios V, Stocker TF, Qin D, Dokken $\mathrm{DJ}$, Ebi KL, Mastrandrea MD, Mach KJ, Plattner GK, Allen SK, Tigno M, Midgley PM, editors. Managing the Risks of Extreme Events and Disasters to Advance Climate Change Adaptation. A Special Report of Working Groups I and II of the Intergovernmental Panel on Climate Change. Cambridge, UK and New York, NY, USA: Cambridge University Press; 2012.

27. Perrow C. Normal Accidents: Living with HighRisk Technologies. Princeton, NJ, USA: Princeton University Press; 1999.

28. Perrow C. The Next Catastrophe: Reducing our Vulnerabilities to Natural, Industrial, and Terrorist 
Disasters. Princeton, NJ, USA: Princeton University Press; 2011.

29. Clarke L. Mission Improbable: Using Fantasy Documents to Tame Disaster. Chicago, IL, USA: University of Chicago Press; 2001.

30. Clarke L. Worst Cases: Terror and Catastrophe in the Popular Imagination. Chicago, IL, USA: University of Chicago Press; 2005.

31. Taleb NN. The Black Swan: The Impact of the Highly Improbable. New York, NY, USA: Random House; 2007.

32. Churchman CW. Wicked problems. Management Science. 1967;14(4):B141-B142.

33. Ward R, Wamsley G. From a painful past to an uncertain future. In: Rubin CB, editor. Emergency Management: The American Experience 1900-2005. Fairfax, VA, USA. Public Entity Risk Institute; 2007. pp. 207-242.

34. King RO. Financing Recovery after a Catastrophic Earthquake or Nuclear Power Incident. Washington, DC, USA: Congressional Research Service 7-5700, Report R41968; 2011. Available from: http:// www.fas.org/sgp/crs/misc/R41968.pdf (accessed on 15 January 2014).

35. Suzuki T. Deconstructing the zero-risk mindset: The lessons and future responsibilities for a postFukushima nuclear Japan. Bulletin of the Atomic Scientists. 2011;67(5):9-18.

36. Von Hippel FN. The radiological and psychological consequences of the Fukushima Daiichi accident. Bulletin of the Atomic Scientists. 2011;67(5):27-36.

37. Leichenko $\mathrm{R}$, O'Brien $\mathrm{KL}$. Environmental Change and Globalization: Double Exposures. New York, NY, USA: Oxford University Press; 2008.

38. Zebrowski C. The nature of resilience. Resilience: International Policies, Practices and Discourses. 2013;1(3):159-173.

39. Leadership Council of the Sustainable Development Solutions Network. An Action Agenda for Sustainable Development: Report for the UN SecretaryGeneral. New York, NY, USA: UN Sustainable Development Solutions Network; 2013. Available from: http:// unsdsn.org/files/2013/11/An-Action-Agenda-for-Sustain able-Development.pdf (accessed on 15 January 2014).

40. Kunreuther HC, Michel-Kerjan EO. At War with the Weather: Managing Large-Scale Risks in a New Era of Catastrophes. Cambridge, UK: MIT Press; 2009.

41. Gall M, Borden KA, Cutter SL. When do losses count? Six fallacies of natural hazards loss data. Bulletin of the American Meteorological Society. 2009;90(6):799-809.

42. Wirtz A, Kron W, Löw P, Steuer M. The need for data: natural disasters and the challenges of database management. Natural Hazards. 2014;70(1):135-157.

43. Gall M, Kreft S. Measuring What Matters? A Suitability Analysis of Loss and Damage Databases for the Climate Change Convention Process. Bonn, Germany: Germanwatch; 2013. Available from: http://www.lossanddamage.net/download/6845.pdf (accessed on 15 January 2014).

44. Norris FH, Stevens SP, Pfefferbaum B, Wyche KF, Pfefferbaum RL. Community resilience as a metaphor, theory, set of capacities, and strategy for disaster readiness. American Journal of Community Psychology. 2008;41(1-2):127-50.

Note: the list of different resiliencies and objects of study is not meant to be exhaustive, but rather illustrative of the range of resiliencies seen in the literature. Community resilience emerges from the combination of all these or what Norris et al. 2008 called adaptive capacities (economic development, social capital, information and communication, and community competence).

45. Sherrieb K, Norris F, Galea S. Measuring capacities for community resilience. Social Indicators Research. 2009;99(2):227-247.

46. Alliance Development Works. WorldRiskIndex 2012. Berlin, Germany: Bündnis Entwicklung Hilft. Available from: http://www.ehs.unu.edu/file/get/10487. pdf (accessed on 15 January 2014).

47. Cutter SL, Burton CG, Emrich CT. Disaster resilience indicators for benchmarking baseline conditions. Journal of Homeland Security and Emergency Management. 2010;7(1):1-22.

48. Cutter S, Osman-Elasha B, Campbell J, Cheong SM, McCormick S, Pulwarty R, Supratid S, Ziervogel G. Managing the risks from climate extremes at the local level. In: Field CB, Barros V, Stocker TF, Qin D, Dokken DJ, Ebi KL, Mastrandrea MD, Mach KJ, Plattner GK, Allen SK, Tignor M, Midgley PM. Managing the Risks of Extreme Events and Disasters to Advance Climate Change Adaptation. A Special Report of Working Groups I and II of the Intergovernmental Panel on Climate Change (IPCC). Cambridge, UK and New York, NY, USA: Cambridge University Press; 2012. pp. 291-338.

49. Tierney K. Disaster governance: Social, political, and economic dimensions. Annual Review of Environment and Resources. 2012;37:341-363.

50. Comfort LK, Boin A, Demchak CC, editors. Designing Resilience: Preparing for Extreme Events. Pittsburgh, PA, USA: University of Pittsburg Press; 2010.

51. United Nations. A New Global Partnership: Eradicate Poverty and Transform Economies through Sustainable Development: The Report of the HighLevel Panel of Eminent Persons on the Post-2015 Development Agenda. New York, NY, USA: United Nations; 2013. Available from: http://www.post2015 hlp.org/the-report (accessed on 15 January 2014).

52. World Bank. Building Resilience: Integrating Climate and Disaster Risk into Development. Lessons from World Bank Group Experience. Washington, DC, USA: The World Bank; 2013. Available from: http://documents.worldbank.org/curated/en/2013/11/ 18513435/building-resilience-integrating-climate-disaster-risk-development-world-bank-group-experiencevol-1-2-main-report (accessed on 15 January 2014). 